\title{
Crescimento inicial de Dimorphandra wilsonii (Fabaceae - Caesalpinioideae) em diferentes condições de fertilidade em solo de cerrado
}

\author{
Márcia Bacelar Fonseca ${ }^{1}$, Marcel Giovanni Costa França ${ }^{2,4}$, Everaldo Zonta ${ }^{3}$ e Victor Giorni ${ }^{2}$
}

Recebido em 19/12/2008. Aceito em 29/09/2009

RESUMO - (Crescimento inicial de Dimorphandra wilsonii (Fabaceae - Caesalpinioideae) em diferentes condições de fertilidade em solo de cerrado). Dimorphandra wilsonii Rizz. é uma espécie arbórea criticamente ameaçada de extinção. Foi descrita para áreas de maior fertilidade no Domínio do cerrado; entretanto, atualmente ocorre em áreas isoladas e de baixa fertilidade natural. Com o objetivo de avaliar a adaptação desta espécie a condições de oligotrofia, plantas foram cultivadas em casa de vegetação em solo destas áreas oligotróficas, mas com diferentes níveis de fertilidade. A partir da análise de fertilidade do solo foram definidas as doses de macronutrientes (NPK) e a dose de calcário a serem utilizadas nos tratamentos que se constituíram de dois níveis de calagem e três níveis de adubação. Após 220 dias do plantio, os tratamentos que aumentaram significativamente o crescimento foram aqueles que receberam adubação com a dose indicada de NPK em solo não corrigido pela calagem e aquele que teve o solo calado e adubado com duas vezes a dose indicada de NPK. A calagem por si só não promoveu maior crescimento, mas propiciou respostas crescentes de crescimento a níveis crescentes de disponibilidade de nutrientes. Foram encontrados nódulos radiculares em todos os tratamentos, e os resultados permitiram concluir que a espécie apresenta requerimento nutricional coerente com sua área de origem no Domínio do Cerrado. Também foi possível ressaltar a fixação biológica de nitrogênio, incomum em Caesalpinioideae, como estratégia adaptativa para crescimento em áreas com baixa oferta de nutrientes.

Palavras-chaves: espécie ameaçada de extinção, fixação biológica de $\mathrm{N}_{2}$, nutrição mineral

ABSTRACT - (Early development of Dimorphandra wilsonii (Fabaceae - Caesalpinioideae) in Cerrado under different soil fertility conditions). Dimorphandra wilsonii Rizz. is a critically endangered tree species. It has been described for sites of higher soil fertility in the Cerrado Domain. However, it occurs nowadays in isolated areas of low natural fertility. To study species adaptation to oligotrophic conditions, plants were grown in a greenhouse in soils from oligotrophic sites but with different levels of fertility. After soil fertility analysis, the macronutrients (NPK) and lime doses to be used in each treatment were defined, resulting in a combination of two liming levels and three fertilization levels. After 220 days, the treatments that significantly increased seedling growth were the one whose substrate was limed and fertilized with twice the prescribed NPK dosage, and the one with the indicated dosage of NPK but no liming. Liming itself did not promote growth enhancement, but favored increased growth response to increasing levels of nutrient availability. Root nodules were found in all the treatments, and the results led to the conclusion that $D$. wilsonii nutritional requirements are consistent with its original distribution sites in the Cerrado Domain. It was also possible to highlight nitrogen biological fixation, an unusual feature in Caesalpinioideae, as an adaptive strategy for survival in areas of low nutrient availability.

Key words: biological fixation of $\mathrm{N}_{2}$, mineral nutrition, risk of extinction

\section{Introdução}

O Cerrado, localizado no Planalto Central do Brasil, é o segundo maior bioma do país em área, apenas superado pela Floresta Amazônica. Segundo Myers et al. (2000), é um dos mais ricos biomas savânicos do mundo, apresentando altos índices de endemismo, sendo considerado como área de absoluta importância para a conservação. Em Minas Gerais, encontramse áreas de cerrado nas regiões do Alto e Médio Jequitinhonha, Alto e Médio São Francisco, Campo das Vertentes, Zona Metalúrgica, Triângulo e Alto Paranaíba, ocupando relevo plano ou suavemente ondulado (Brandão 2000). O processo de ocupação territorial de Minas Gerais ocasionou a substituição de amplas áreas de Cerrado por culturas agrícolas, implantação de pastagens para a pecuária ou a própria utilização da vegetação como matéria prima para as carvoarias que abastecem as siderúrgicas. Em decorrência deste modelo de desenvolvimento, a cobertura vegetal deste bioma reduziu-se de maneira drástica, acarretando a perda da ampla diversidade e, conseqüentemente, favorecendo o processo de extinção de espécies.

Dimorphandra wilsonii Rizz. (Fabaceae - Caesalpinioideae) é uma espécie arbórea do Domínio do Cerrado, descrita para o limite entre o cerradão e a mata semidecídua
(Rizzini 1969), e é uma dentre as muitas espécies ameaçadas de extinção em decorrência da degradação do seu habitat. Rizzini \& Matos Filho (1986), em viagem para a prospecção de novos exemplares desta espécie em Paraopeba-MG, descreveram a existência de 18 indivíduos distribuídos em três fazendas da região. Atualmente, segundo Fernandes et al. (2007), existem somente 10 indivíduos adultos sobrevivendo em meio a áreas de pastagens de Brachiaria sp, em duas áreas na mesma região ( $\left(9^{\circ} 16^{\prime} \mathrm{S}\right.$ e $\left.44^{\circ} 24^{\prime} \mathrm{W}\right)$, e nenhum outro relato. Devido à destruição do seu hábitat, da sua ocorrência estar restrita e sua população estar isolada de áreas remanescentes do Cerrado, $D$. wilsonii foi incluída na Lista Vermelha das Espécies Ameaçadas (IUCN 2006) na categoria criticamente ameaçada. Assim, é de considerável importância para a conservação da biodiversidade o melhor entendimento acerca da relação biológica estabelecida entre a espécie e seu ambiente, a fim de subsidiar as medidas de conservação de espécies raras e endêmicas e seus ecossistemas (Primack \& Rodrigues 2001; Heywood \& Iriondo 2003).

As primeiras teorias que buscaram explicar os tipos vegetacionais do cerrado se basearam nas pesquisas sobre a influência do clima, da deficiência hídrica e da ação antrópica, incluindo o fogo. Seguiu-se a estas teorias uma abordagem

\footnotetext{
Fundação Zôo-Botânica de Belo Horizonte, Belo Horizonte, MG, Brasil

2 Universidade Federal de Minas Gerais Instituto de Ciências Biológicas, Departamento de Botânica, , Belo Horizonte, MG, Brasil

Universidade Federal Rural do Rio de Janeiro, Instituto de Agronomia, Departamento de Solos, Seropédica, RJ, Brasil

4 Autor para correspondência: marcel@icb.ufmg.br
} 
que associava a morfologia das plantas e as fisionomias vegetacionais ocorrentes neste bioma à baixa fertilidade do solo. Portanto, a oligotrofia dos solos, aliada às demais condições ambientais e ecológicas, determinaria o gradiente vegetacional entre o campo limpo e o cerradão (Rawitscher et al. 1943; Alvim \& Araújo 1952; Alvim 1954; Arens 1963; Ferri 1977). Para Grime (1977) e Chapim (1980), as espécies de habitats que apresentam fatores limitantes ao crescimento, tais como água, luz e nutrientes, podem desenvolver mecanismos fisiológicos e morfológicos para sobreviverem nestes ambientes. Em resposta à oligotrofia dos solos, as plantas do cerrado, usualmente, têm crescimento lento, estocam carboidratos em estruturas subterrâneas e em componentes do caule e das folhas e podem estabelecer relações simbióticas com microorganismos para adquirirem especialmente fósforo e nitrogênio, elementos encontrados em baixas concentrações (Franco 2002). Estas características fisiológicas e morfológicas, acrescidas à plasticidade fenotípica relacionada às variadas condições ambientais existentes, permitiram que algumas espécies se estabelecessem nos diferentes tipos de formações vegetais deste bioma. A adaptabilidade das espécies à condição de oligotrofia do solo deve ser investigada de forma individual, pois algumas espécies respondem a uma maior oferta de nutrientes e outras não (Haridasan 2000), e, quando o objetivo é a conservação de espécies raras, endêmicas e ameaçadas, torna-se necessário compreender a relação que a espécie em questão tem com o seu ambiente para se estabelecerem parâmetros que auxiliem na sua conservação tanto in situ quanto ex situ.

Devido ao fato de $D$. wilsonii ter sua ocorrência descrita para a mata semidecídua, em transição com Cerrado ou cerradão, áreas de solos mais férteis, é possível pressupor que a mesma responda favoravelmente à oferta suplementar de nutrientes ou possa apresentar estratégias para sobreviver às condições nutricionais limitantes e comuns aos solos do Cerrado. Assim, para verificação desta hipótese, comparouse o crescimento de plantas jovens de $D$. wilsonii cultivadas em solo natural da área de ocorrência atual da espécie e neste corrigido a diferentes níveis de fertilidade.

\section{Material e métodos}

O estudo foi conduzido de setembro de 2005 a abril de 2006 no Jardim Botânico da Fundação Zôo-Botânica de Belo Horizonte, em Belo Horizonte, Minas Gerais ( $19^{\circ} 55^{\prime} \mathrm{S}$ e $\left.43^{\circ} 56^{\prime} \mathrm{W}\right)$. Frutos dos 10 indivíduos remanes- centes de $D$. wilsonii foram coletados e beneficiados para retirada das sementes. Estas foram limpas, selecionadas de acordo com a integridade do tegumento, regularidade da forma e uniformidade de tamanho, totalizando um lote de 90 sementes. Para desinfestá-las o procedimento usado foi o de imersão em álcool 70\% (v/v), seguido de hipoclorito de sódio 2,5\% $(\mathrm{v} / \mathrm{v})$ e lavagem por dez vezes em água destilada. Posteriormente, foram escarificadas mecanicamente, com lixa d'água, para quebra de dormência, semeadas em bandejas de isopor de 128 células de $25,9 \mathrm{~cm}^{3}$ cada e colocadas em câmara para germinação, FANEM - 347/CDG, à temperatura de $28^{\circ} \mathrm{C}$ e fotoperíodo de $12 \mathrm{~h}$. As plântulas obtidas foram transplantadas para sacos plásticos, com capacidade de $6 \mathrm{dm}^{3}$.

Como substrato para as plantas, foi utilizado a camada superficial (0-20 $\mathrm{cm}$ ) de um Latossolo da região de ocorrência da espécie. Uma sub-amostra foi seca ao ar, passada por uma peneira de $2 \mathrm{~mm}$ e submetida à análise química para avaliação da fertilidade. $\mathrm{O} \mathrm{pH}$ foi medido em água; $\mathrm{Ca}^{2+}$, $\mathrm{Mg}^{2+}$ e $\mathrm{Al}^{3+}$ trocáveis foram determinados no extrato de $\mathrm{KCl}$ e $\mathrm{P}, \mathrm{K}$ e Mn no extrato de Mehlich.

O delineamento experimental utilizado foi em blocos casualizados, em esquema fatorial $2 \times 3$ (níveis de calagem $\times$ níveis de adubação), perfazendo 6 tratamentos com 10 repetições cada, totalizando 60 plantas. $\mathrm{O}$ experimento foi conduzido em casa de vegetação e os tratamentos para níveis de fertilidade estão descritos na Tab. 1.

Para os tratamentos que receberam a calagem, o solo ficou incubado por 15 dias para elevação do $\mathrm{pH}$, redução da solubilidade do alumínio, aumento de cálcio e magnésio trocáveis e a porcentagem de saturação de bases (Brady 1989). A dose de calcário utilizada foi de $0,15 \mathrm{~g}$ de calcário dolomítico PRNT 93\% $100 \mathrm{~g} \mathrm{de} \mathrm{solo}^{-1}$. A fertilização foi feita por meio de solução nutritiva, e a dose utilizada de macronutrientes (NPK), aplicada em quatro parcelas $(60,100,140$ e 120 dias após a emissão da radícula), apresentava as seguintes concentrações: $0,015 \mathrm{~g}$ de P $100 \mathrm{~g} \mathrm{de} \mathrm{solo}^{-1}, 0,010$ $\mathrm{g}$ de $\mathrm{N} 100 \mathrm{~g}_{\text {de }}$ solo $^{-1}$ e $0,010 \mathrm{~g}$ de $\mathrm{K}_{2} \mathrm{O} 100 \mathrm{~g}$ de solo ${ }^{-1}$. Foram utilizados como fontes de nutrientes os seguintes reagentes analíticos: $\mathrm{H}_{3} \mathrm{PO}_{4}, \mathrm{KH}-$ ${ }_{2} \mathrm{PO}_{4}$ e $\mathrm{H}_{2} \mathrm{NCONH}_{2}$ (uréia). Durante o experimento, a umidade do solo foi mantida em $70 \%$ da capacidade de campo, aferida através de pesagens e reposições de água periódicas.

A avaliação do crescimento foi feita 220 dias após a semeadura e os parâmetros avaliados foram: altura, diâmetro do caule, número de folhas, área foliar, massa seca da raiz, do caule, das folhas, massa seca total e razão de massa seca raiz: parte aérea. Para a obtenção da área foliar, as folhas foram escaneadas e a área calculada através do programa Quantikov Image Analyzer/Easy Quantify (Pinto 2001). A altura das plantas foi medida do solo ao ápice foliar, e o diâmetro do caule foi tomado na região do colo. Para a obtenção da massa seca, as plantas foram secas à temperatura de 60 ${ }^{\circ} \mathrm{C}$ em estufa de secagem de circulação de ar forçada - FANEM - 320, até a obtenção de peso constante.

Os nódulos verificados nas raízes das plantas de cada tratamento foram retirados manualmente, contados, com o auxílio de um contador manual, e registrados.

Todos os dados obtidos nas avaliações foram submetidos à análise de variância fatorial (ANOVA), utilizando o programa MINITAB 14 $\left(\right.$ MINITAB $^{\circledR}$ Statistical Software for Windows 2006). As comparações múltiplas entre as médias foram feitas usando o teste de Duncan a $5 \%$ de probabilidade, e o programa utilizado para esta análise foi o SPSS (SPSS ${ }^{\circledR}$ for Windows 2006).

Tabela 1. Tratamentos aplicados ao solo para o cultivo de Dimorphandra wilsonii por 220 dias em casa de vegetação.

\begin{tabular}{cl}
\hline Tratamento & Solo \\
\hline T1 & Natural $=$ solo de cerrado sem calagem e sem adubação \\
T2 & Natural $+2 \times$ NPK $=$ solo de cerrado $+2 \times$ dose de NPK \\
T3 & Calado $=$ solo de cerrado + calagem \\
T4 & Calado + NPK $=$ solo de cerrado + calagem + dose de NPK \\
T5 & Calado $+2 \times$ NPK $=$ solo de cerrado + calagem $+2 \times$ dose de NPK \\
T6 &
\end{tabular}




\section{Resultados}

O solo utilizado e de ocorrência atual da espécie foi classificado como de baixa fertilidade natural, devido ao baixo valor de saturação de bases (valor $\mathrm{V}$ decorrente), principalmente pela alta saturação por alumínio (valor m) (Tab. 2). Assim, para elevar a fertilidade do solo, tornou-se necessário efetuar a calagem e aumentar os teores de N, P e K por meio da aplicação de calcário e adubação, respectivamente.

Tabela 2. Resultado da análise química de fertilidade do solo coletado na área atual de ocorrência Dimorphandra wilsonii (Paraopeba - MG, $19^{\circ} 16^{\prime} \mathrm{S}$ e $44^{\circ}$ $\left.24^{\prime} \mathrm{W}\right)$.

\begin{tabular}{|c|c|c|c|c|c|c|c|c|c|c|c|}
\hline $\mathrm{pH}$ & & $\mathrm{Cmol}$ & $\mathrm{dm}^{-3}$ & & $\mathrm{mg}$ & & & $\mathrm{nol}_{\mathrm{c}} \mathrm{d}$ & & & 0 \\
\hline $\mathrm{H}_{2} \mathrm{O}$ & $\mathrm{H}+\mathrm{Al}$ & $\mathrm{Al}^{3+}$ & $\mathrm{Ca}^{2+}$ & $\mathrm{Mg}^{2+}$ & $\mathrm{P}$ & $\mathrm{K}$ & $\mathrm{SB}$ & $\mathrm{T}$ & $\mathrm{t}$ & $\mathrm{m}$ & V \\
\hline 5,2 & 4,62 & 1,09 & 0,38 & 0,06 & $<1$ & 32 & 0,52 & 5,14 & 1,61 & 67,8 & 10,0 \\
\hline
\end{tabular}

$\mathrm{H}_{2} \mathrm{O}=\mathrm{pH}$ em água, $\mathrm{SB}=$ soma de bases, $\mathrm{T}=$ Capacidade de troca de cátions, $\mathrm{t}=$ Capacidade efetiva de troca de cátions, $\mathrm{m}=$ índice de saturação por alumínio, $\mathrm{V}=$ índice de saturação por bases.

Os resultados da ANOVA revelaram efeito da adubação, da calagem e da interação entre os dois fatores, para a maioria dos parâmetros de crescimento avaliados. Assim, observou-se que, após 220 dias de cultivo, as plantas crescidas nos tratamentos T2 (solo natural adubado com a dose indicada de NPK) e T6 (solo calado e adubado com duas vezes a dose de NPK) apresentaram crescimento significativamente maior, quando comparadas aos demais tratamentos, para os parâmetros altura, diâmetro do caule e área foliar (Fig. 1-A, B e C).

A massa seca de caules foi igual nos tratamentos T2 e T6, e os valores destes foram maiores quando comparados aos valores encontrados nos outros tratamentos (Fig. 2A). Os resultados obtidos para a massa seca de folhas convergem com os dados registrados para a área foliar. As plantas crescidas em solo dos tratamentos T2 e T6 apresentaram concomitantemente maior massa e área foliar, quando comparadas com as plantas que cresceram nos demais tratamentos (Fig. 1C e 2B). Para a massa seca da raiz, observou-se que não houve diferença significativa entre os tratamentos (Fig. 2C).

A avaliação da massa seca total (MST) corroborou aos resultados já descritos (Fig. 3A). Verificou-se que os tratamentos que favoreceram maior acúmulo de MST ao final do período de crescimento foram também aqueles que obtiveram médias mais altas para os indicadores de crescimento avaliados anteriormente (T2 e T6). Nos tratamentos T1 e T4 (solo de cerrado calado) onde a fertilidade do solo foi menor, em decorrência da ausência de correção química ou adubação, os valores para a razão entre a massa seca da raiz e a massa seca da parte aérea foram maiores (Fig. 3B). Observou-se ainda que nos tratamentos cujos solos foram adubados com NPK (T2, T3, T5 e T6), os valores para esta razão foram menores do que nos demais.
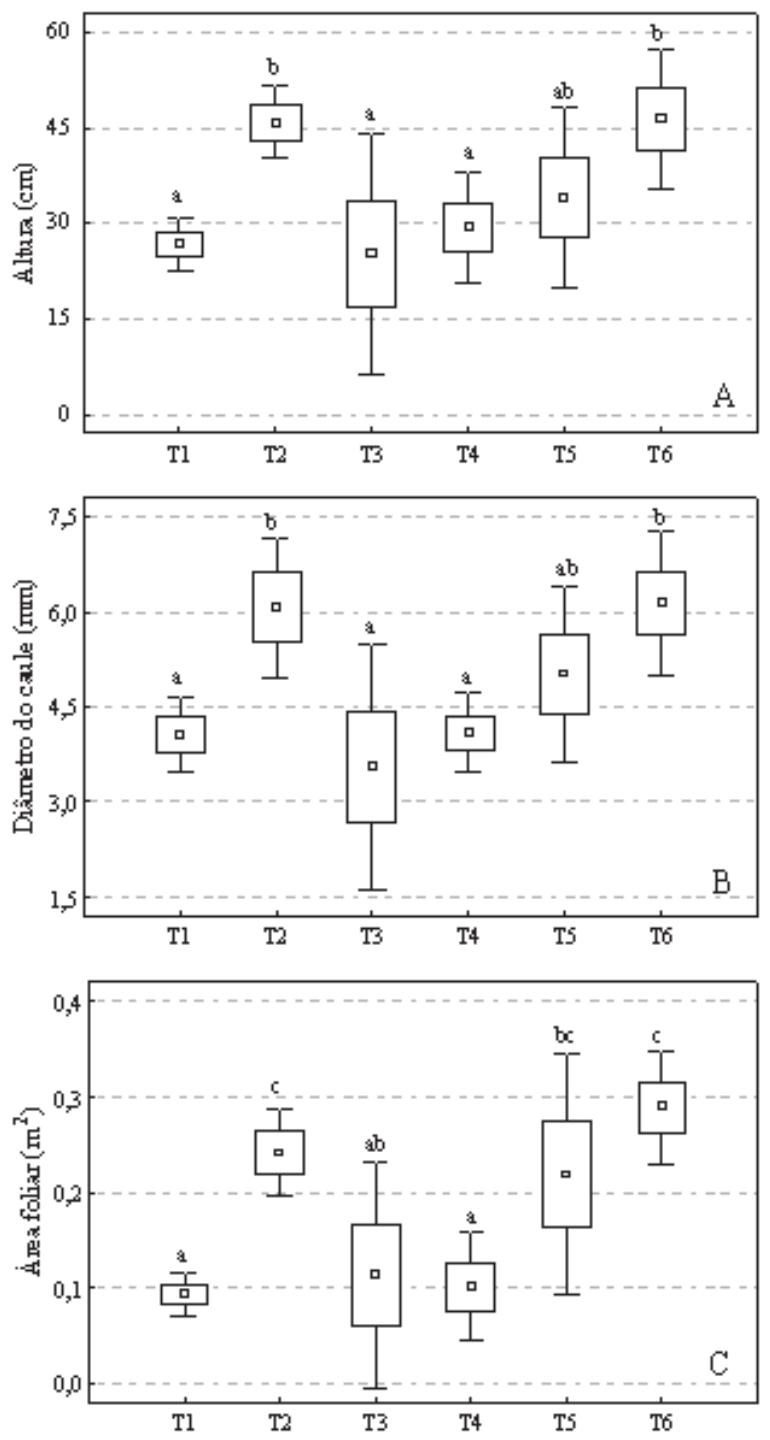

Figura 1. Efeito da fertilidade do solo sobre altura da planta (A), diâmetro do caule (B), e área foliar (C) após 220 dias de cultivo de Dimorphandra wilsonii. Médias ( $\square$ ) seguidas pelas mesmas letras não diferem entre si pelo teste de Duncan $(\mathrm{P} \leq 5 \%)$.

Nódulos radiculares foram verificados em todos os tratamentos e observou-se que naqueles que não receberam adubação (T1 e T4) o número de nódulos foi maior quando comparado aos resultados encontrados nos outros tratamentos e o aumento da fertilidade do solo reduziu o número de nódulos em solos que receberam ou não a calagem (Fig. 3C).

\section{Discussão}

Em nosso estudo evidenciamos que as plantas de $D$. wilsonii responderam de forma positiva à adubação, mas esta resposta diferiu entre solo com e sem calagem. Verificou-se que quando não houve correção do $\mathrm{pH}$ através da calagem, a resposta à adubação crescente mostrou um ótimo no nível recomendado de adubação, respondendo de forma negativa na dose mais elevada (T3), quando este tratamento foi com- 

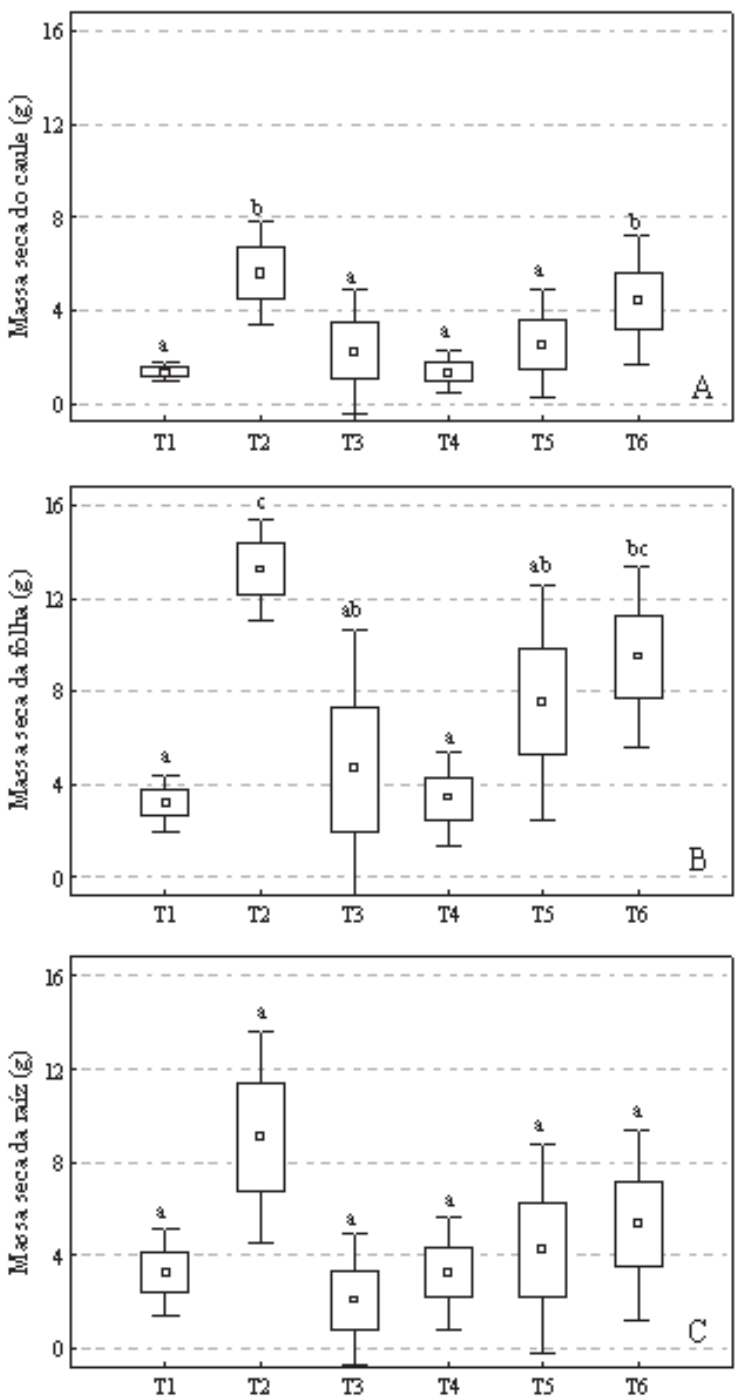

Figura 2. Efeito da fertilidade do solo sobre o acúmulo de massa seca no caule (A), na folha (B) e na raiz (C) após 220 dias do cultivo de Dimorphandra wilsonii. Médias ( $\square$ ) seguidas pelas mesmas letras não diferem entre si pelo teste de Duncan $(\mathrm{P} \leq 5 \%)$.

parado ao de menor nível (T2). A calagem do solo, por outro lado, permitiu às plantas expressarem um maior crescimento na dose mais elevada de adubação (T6). Assim, embora a calagem por si só não tenha favorecido o crescimento (revelado pela falta de diferenças entre os dois níveis de calagem dentro de cada nível de adubação), ela favoreceu a resposta à adubação, refletindo a interação destes dois fatores.

A evidente resposta de crescimento ao aumento na fertilidade do solo, constatada neste experimento, mesmo sem correção da sua acidez nos permite evidenciar que a oligotrofia do substrato utilizado, e comum aos solos de cerrado, limita o crescimento da espécie e nos permite inferir que $D$. wilsonii apresenta requerimento nutricional coerente com a disponibilidade de nutrientes do seu ambiente de origem, o qual é relativamente fértil. Resultados que evidenciam a adaptação de espécies vegetais às condições de oligotrofia
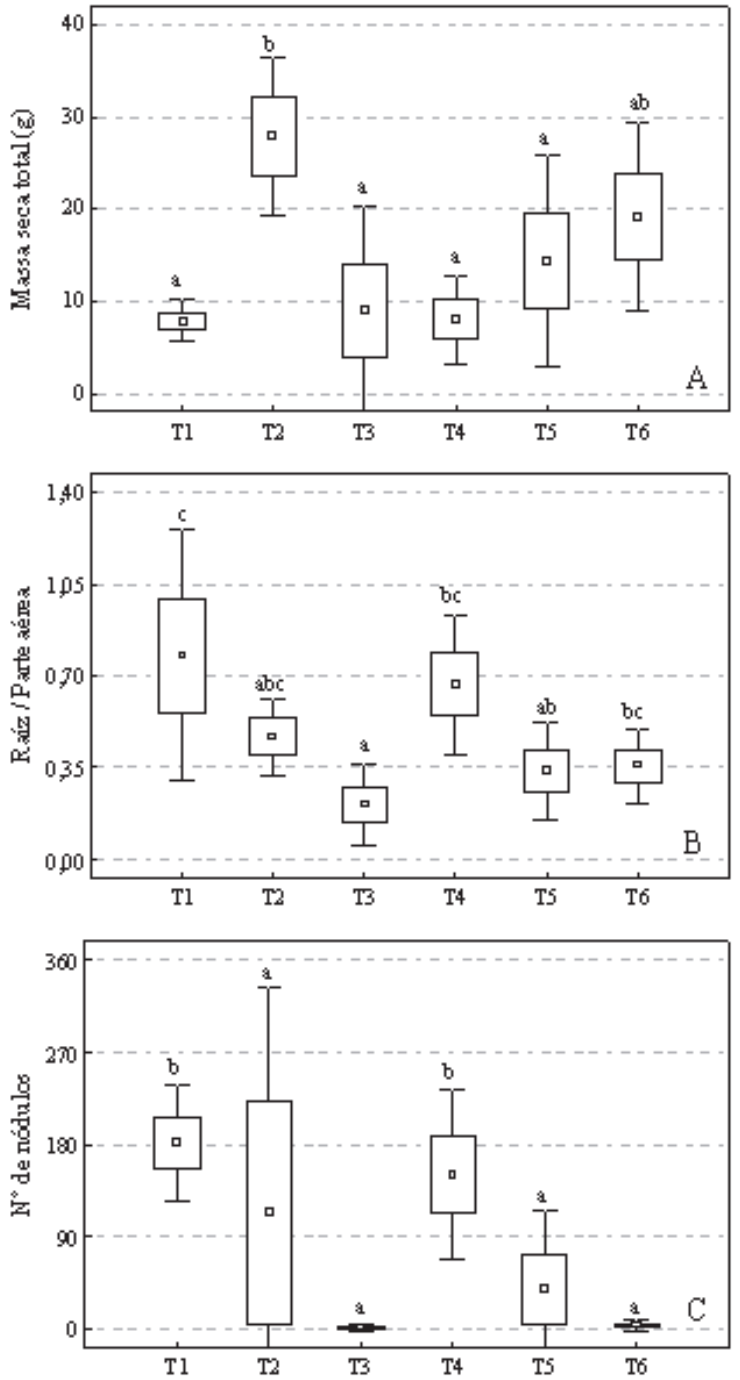

Figura 3. Efeito da fertilidade do solo sobre o acúmulo de massa seca total (A) a relação raiz: parte aérea (B) e o número de nódulos radiculares $(\mathrm{C})$ após 220 dias de cultivo de Dimorphandra wilsonii. Médias ( $\square$ ) seguidas pelas mesmas letras não diferem entre si pelo teste de Duncan $(\mathrm{P} \leq 5 \%)$.

do solo, mas sem demonstrarem um maior crescimento das mesmas quando cultivadas em solos corrigidos quimicamente, foram apresentados por Gomes \& Shepherd (2000), Mendes et al. (2005) e Rosa et al. (2005).

Virgens Filho et al. (2001); Oliveira Júnior et al. (2005); Silva et al. (2005) e Venturin et al. (2005) relataram o favorecimento do crescimento propiciado pela calagem e adubação mineral em algumas espécies ocorrentes em solos ácidos e de baixa fertilidade. O nosso experimento, no entanto, evidencia que o efeito da calagem foi o de potencializar o efeito de uma maior adubação e que isoladamente não favorece o crescimento da espécie. A causa da baixa capacidade produtiva dos solos ácidos do Cerrado pode estar relacionada à atuação isolada do baixo $\mathrm{pH}$, que influencia o desenvolvimento vegetal por interferir na disponibilidade de nutrientes no solo, ou pela ação deste acrescido a um conjunto de outros fatores, 
como a toxidez de certos elementos presentes em concentrações excessivas na solução do solo, alumínio e manganês, e/ou à deficiência de alguns nutrientes, tais como fósforo, magnésio e cálcio (Malavolta \& Kliemann, 1985). Ainda, as características químicas dos solos do Cerrado sugerem muito fortemente que as respostas à aplicação de calcário sejam devidas, principalmente, à eliminação do alumínio tóxico $\left(\mathrm{Al}^{3+}\right)$ e, além disso, a efeitos na disponibilidade dos demais elementos (Malavolta et al. 1977).

Os dados obtidos para avaliação do acúmulo de massa seca nos permitiram constatar que $D$. Wilsonii, quando cresce em condições oligotróficas (T1 e T4), intensifica o desenvolvimento de raízes em relação ao desenvolvimento da parte aérea. Além disso, nestes níveis naturais de fertilidade do solo (T1 e T4) foi observado um maior número de nódulos radiculares, que pode ser traduzido como um possível aumento no aporte de nitrogênio proveniente da fixação biológica. Estes resultados demonstram respostas adaptativas apresentadas pela espécie visando à melhoria do seu status nutricional. Respostas semelhantes têm sido frequentemente verificadas (Clarkson 1967; Davidson 1969; Chapim 1980; Wrigth \& Westoby 2000). Por outro lado, plantas crescidas em solos adubados, calados ou não (T2, T3, T5, T6) expressaram um maior investimento na estrutura foliar, isto é, em massa seca de folha e em área foliar, do que em massa seca de raiz, uma resposta que potencializa a capacidade fotossintética da parte aérea. Assim, estes resultados evidenciam que $D$. wilsonii apresenta o balanço funcional entre raiz e parte aérea condizente com a oferta de nutrientes do ambiente em que se desenvolve, investindo em massa seca de raiz quando cresce em solo oligotrófico e em massa seca da parte aérea quando cresce em solo de maior fertilidade. Segundo Chapim (1980), espécies de habitats com maior oferta de nutrientes apresentam considerável plasticidade adaptativa quanto à razão raiz: parte aérea e geralmente têm uma alta razão em baixa oferta e uma baixa razão sob maior oferta de nutrientes, quando comparadas com espécies de habitats pobres em nutrientes. Embora Aerts \& Chapim (2000) apontem para um aumento no comprimento radicular específico como sendo muitas vezes uma solução evolutiva mais relevante do que um aumento na razão de massa entre raiz e parte aérea, no que diz respeito ao aumento na eficiência na absorção de nutrientes em solos pouco férteis, no caso de D. wilsonii a razão de massa mostrou-se fortemente responsiva à disponibilidade nutricional, mostrando ser um caráter fortemente plástico, o que não exclui a possibilidade de que aumentos no comprimento radicular específico em resposta à baixa fertilidade também se expressem nesta espécie. Um aspecto interessante e que merece futuras investigações foi o fato de que, enquanto as plantas T2 tiveram a maior razão de massa entre raiz e parte aérea vinculada a um maior crescimento global das plantas, quando comparadas às plantas T1 (controle), a resposta das plantas T3 não foi equivalente: a menor razão não veio acompanhada de maior crescimento, pois enquanto as partes aéreas tenderam a crescer um pouco mais do que em T1, as raízes acumularam menos massa. É possível que problemas associados à toxicidade radicular tenham levado a este padrão de resposta.

A associação com bactérias fixadoras de nitrogênio é uma estratégia incomum em Caesalpinioideae. Faria et al. (1989), comparando a ocorrência da nodulação nas três sub-famílias de Fabaceae ocorrentes nas principais fitofisionomias do sudeste do Brasil, verificaram que somente $23 \%$ das espécies de Caesalpinioideae examinadas nodulavam e que este número era muito menor quando comparado aos 90\% de nodulação verificados em Mimosoideae e 97\% em Papilionoideae. Dimorphandra wilsonii mostrou-se fortemente plástica no que diz respeito ao grau de nodulação de suas raízes, diminuindo o grau de associação com bactérias fixadoras de nitrogênio quando as condições químicas do solo eram mais favoráveis. Sabe-se que a taxa de fixação de $\mathrm{N}$ é sensível ao status nutricional das plantas e que um aumento na disponibilidade deste elemento leva a uma redução na taxa de fixação como forma de reduzir os custos energéticos envolvidos (Aerts \& Chapim, 2000). Considerando-se a importância do P no fornecimento de energia para o processo de fixação (Aerts \& Chapim, 2000) e considerando-se a deficiência em $\mathrm{P}$ dos solos de cerrado, tal plasticidade assume ainda maior relevância.

A responsividade do crescimento da espécie à maior oferta nutricional nos ajuda a explicar o padrão de distribuição geográfica original da espécie, e seu padrão de crescimento sob baixa oferta de nutrientes ajuda a explicar sua habilidade atual em crescer em ambientes de menor fertilidade do cerrado. Nossos resultados não irão alterar o status de ameaça de $D$. wilsonii. Para isto, seria necessário, no mínimo, recuperar seu hábitat e interligá-lo a áreas remanescentes. Entretanto, a partir deste estudo, poderemos contribuir para a manutenção do germoplasma desta espécie, pelo menos ex situ. Seria de interesse uma investigação acerca do elemento mineral ou dos elementos minerais que são efetivamente limitantes ao seu crescimento, pois sabendo que a absorção do nitrogênio pode ser facilitada pela fixação biológica nos recai a hipótese acerca do fósforo, devido sua deficiência nos solos deste bioma. Também seria importante a investigação sobre a especificidade e efetividade da relação simbiótica estabelecida entre $D$. Wilsonii e a bactéria, bem como o real aporte de nitrogênio advindo desta. Estes e outros estudos são fundamentais para conhecermos a biologia desta espécie e, no curto prazo, garantir a conservação do seu germoplasma.

\section{Agradecimentos}

À Fundação Zôo-Botânica da Prefeitura de Belo Horizonte por permitir a condução dos experimentos e ao Programa de Pós-graduação em Biologia Vegetal da Universidade Federal de Minas Gerais (UFMG).

\section{Referências bibliográficas}

Aerts, R. \& Chapim III, F.S. 2000. The mineral nutrition of wild plants revisited: a re-evaluation of processes and patterns. Advances in Ecological Research 30: 1-67.

Alvim, P.T. 1954. Teoria sobre a formação dos campos cerrados. Revista Brasileira de Geografia 7: 496-498. 
Alvim, P.T. \& Araújo, W.A. 1952. El suelo como factor ecológico en el desarrollo de la vegetación en el centro-oeste del Brasil. Turrialba 2: $153-160$.

Arens, K. 1963. As plantas lenhosas dos campos cerrados como flora adaptada às deficiências minerais do solo. Pp. 251-265. In: Ferri, M. G. Simpósio sobre o cerrado. São Paulo, EDUSP.

Brady, N.C. Natureza e propriedades dos solos. Rio de Janeiro: Livraria Freitas Bastos, 1989. Rio de Janeiro.

Brandão, M. 2000. Cerrado. Pp. 55-63. In: Mendonça, M.P. \& Lins, L.V. (orgs.). Lista vermelha das espécies ameaçadas de extinção da flora de Minas Gerais. Belo Horizonte, Fundação Biodiversitas, Fundação Zôo-Botânica.

Chapim III, F.S. 1980. The mineral nutrition of wild plants. Annual Review Ecology and Systematics 11: 233-260.

Clarkson, D.T. 1967. Phosphorus supply and growth rate in species of Agrostis L. Journal of Ecology 55: 11-118.

Davidson, R.L. 1969. Effects of soil nutrients and moisture on root/shoot ratios in Lolium perenne L. and Trifolium repens L. Annals of Botany 33: $571-577$.

Faria, S.M. de; Lewis, G.P.; Sprent, J.I.; Sutherland, J.M. 1989. Occurrence of nodulation in the Leguminosae. New Phytologist 111: 607-619.

Fernandes, F.M.; Fonseca, A.G.; Kaechele, K.; Goulart, M.F.; Marinho, W.; Souza, H.A.V.; Queiroz, A.R.; Giorni, V.; Oliveira, G.; Rodrigues, M.J.; Bacelar, M. \& Lovato, M.B. 2007. Pp. 87-98. Tentando evitar mais uma extinção: o caso do Faveiro de Wilson (Dimorphandra wilsonit Rizz.). In: T.S. Pereira, M.L.M.N. Costa \& P.W. (orgs.). Recuperando o verde para as cidades - A Experiência dos Jardins Botânicos Brasileiros. Rio de Janeiro, RBJB.

Ferri, M.G. 1977. Ecologia dos cerrados. Pp. 15-33. In: Ferri, M.G. IV Simpósio sobre o cerrado. São Paulo, EDUSP

Franco, A.C. 2002. Ecophysiology of woody plants. Pp. 178-197. In: Oliveira, P.S. \& Marquis, R.J. (Eds.). The cerrado of Brazil: ecology and natural history of neotropical savanna. New York, Columbia University Press.

Gomes, M.A.N. \& Shepherd, S.L.K. 2000. Estudos de nutrição mineral in vitro relacionado à adaptação de Sinningia allagophylla (Martius) Wiehler (Gesneriaceae) às condições de cerrado. Revista Brasileira de Botânica 23: 153-159.

Grime, J.P. 1977. Evidence for the existence of three primary strategies in plants and its relevance to ecological and evolutionary theory. The American Naturalist 111: 1169-1194.

Haridasan, M. 2000. Nutrição mineral de plantas nativas do cerrado. Revista Brasileira de Fisiologia Vegetal 12: 54-64.

Heywood, V.H. \& Iriondo, J.M. 2003. Plant conservation: old problems, new perspective. Biological Conservation 113: 321-335.
IUCN. 2006. Red List of Threatened Species. Disponível em: < http:// www.iucnredlist.org $>$.

Malavolta, E. \& Kliemann, H.J. 1985. Desordens nutricionais no cerrado. Potafos, Piracicaba, São Paulo.

Malavolta, E.; Sarruge, J.R.; Bittencourt, V.C. 1977. Toxidez de alumínio e de manganês. Pp. 275-301. In: Ferri, M.G. (Coord.). IV Simpósio sobre o cerrado. Editora Itatiaia, Belo Horizonte; EDUSP, São Paulo.

Mendes, A.D.R.; Martins, E.R.; Fernandes, L.A. \& Marques, C.C.L. 2005. Produção de biomassa e de flavonóides totais por Fava d'anta (Dimorphandra mollis Benth.) sob diferentes níveis de fósforo em solução nutritiva. Revista Brasileira de Plantas Medicinais 7: 7-11.

MINITAB $^{\circledR}$. 2006. Statistical Software for Windows, ver. 14.

Oliveira Júnior, A.C.; Fanquin, V.; Pinto, J.E.B.P.; Lima Sobrinho, R.R. \& Bertolucci, S.K.V. 2005. Teor e rendimento de óleo essencial no peso fresco de arnica, em função de calagem e adubação. Horticultura Brasileira 23: 735-739.

Myers, N.R.A.; Mittermeier, C.G.; Fonseca, G.A.B. \& Kent, J. 2000. Biodiversity hot spots for conservation priorities. Nature 403: 853-858.

Pinto, L.C.M. 2001. Progama Quantikov Image Analyzer/Easy Quantify.

Primack, R.B. \& Rodrigues, E. 2001. Biologia da Conservação. Londrina Ed. Vida.

Rawitscher, F.K.; Ferri, M.G. \& Rachid, M. 1943. Profundidade dos solos e vegetação em campos cerrados do Brasil meridional. Anais Academia Brasileira de Ciências 15: 267-294.

Rizzini, C.T. 1969. Espécies novas de árvores do planalto central brasileiro. Anais Academia Brasileira de Ciências 41: 239-244.

Rizzini, C.T. \& Matos Filho, A. de. 1986. Espécies vegetais em extinção. Boletim da Sociedade Brasileira para a Conservação da Natureza 21: 99-104.

Rosa, M.E.C.; Naves, R.V. \& Oliveira Júnior, J.P. 2005. Produção e crescimento de mudas de mangabeira (Hancornia speciosa Gomes) em diferentes substratos. Pesquisa Agropecuária Tropical 35: 65-70.

Silva, E.B.; Gonçalves, N.P. \& Pinho, P.J. 2005. Limitações nutricionais para crescimento de mudas de umbuzeiro em latossolo vermelho distrófico no norte de Minas. Acta Scientiarum Agronomy 27: 55-59.

SPSS $^{\circledR}$.2006. For windows.

Venturin, N.; Souza, P.A.; Macedo, R.L.G. \& Nogueira, F.D. 2005. Adubação mineral da candeia (Eremanthus erythropappus (Dc.) McLeish). Floresta 35: 211-219.

Virgens Filho, A.C.; Moreira, A. \& Castro, P.R.C. 2001. Efeito da calagem e adubação da seringueira no estado nutricional e produção de borracha seca. Pesquisa Agropecuária Brasileira 36: 1019-1026.

Wrigth, I.J. \& Westoby, M. 2000. Cross-species relationships between seedling relative growth rate, nitrogen productivity and root vs leaf function in 28 Australian woody species. Functional Ecology 14: 97-107. 